\title{
APLICACIÓN DE UN ENTORNO INFORMÁTICO PARA TEORÍA DEL DISEÑO, BASADO EN EL
}

\section{APPLICATION OF A COMPUTER ENVIRONMENT FOR THEORY OF DESIGN, BASED ON CONSTRUCTIVISM}

Concepción del Carmen Bedón Vaca ${ }^{1}$ Verónica Maribel Pailiacho Mena²

1. Arquitecta Interiorista. Magister en Tecnologías para la Gestión y Práctica Docente. Pontificia Universidad Católica del Ecuador Ambato, Docente de la Escuela de Diseño Industrial, Ambato (Ecuador). E-mail: cbedon@pucesa.edu.ec

2. Ingeniera en Sistemas Informáticos. Magister en Gerencia Informática. Pontificia Universidad Católica del Ecuador Ambato, Docente de la Escuela de Ingeniería en Sistemas, Ambato (Ecuador). E-mail: vpailiacho@pucesa.edu.ec

\section{Citación sugerida:}

Bedón Vaca, C.C. y Pailiacho Mena, V.M. (2017). Aplicación de un entorno informático para teoría del diseño, basado en el constructivismo. 3C TIC: Cuadernos de desarrollo aplicados a las TIC, 6(4), 27-41. DOI: <http://dx.doi.org/10.17993/3ctic.2017.58.27-41/>. 
El presente trabajo parte de una investigación centrada en la transformación de conceptos a imágenes, con la finalidad de incrementar el conocimiento en el área de la teoría del diseño, aplicando el constructivismo como base del modelo didáctico sustentado en tecnologías web y la combinación con el trabajo colaborativo para la resolución de supuestos prácticos. El centro de la propuesta se basa en la metodología de operacionalización de un aula virtual, la cual parte de una evaluación formativa dirigida a la estructura de la asignatura, para establecer actividades, tiempos, responsables, objetivos, estrategias del metaaprendizaje y contenidos a manejarse a través de los recursos de la web 2.0, dentro de la plataforma virtual MOODLE. El resultado final es una estructura metafórica como eje del aula virtual, la cual se enfoca en el estudiante y sus niveles de aprendizaje, para la construcción del conocimiento de una asignatura teórica, haciéndola visualmente atractiva para el proceso de enseñanza-aprendizaje en modalidad B-Learning.

\section{ABSTRACT}

This work is based on an investigation focused on the transformation of concepts into images, with the aim of increasing knowledge in the area of design theory, applying constructivism as the basis of the didactic model based on web technologies and the combination with the work Collaborative for the resolution of practical assumptions. The center of the proposal is based on the methodology of operationalization of a virtual classroom, which starts from a formative evaluation directed to the subject structure, to establish activities, times, leaders, objectives, meta-learning strategies and contents to be handled through the resources of the web 2.0, within the virtual platform MOODLE. The final result is a metaphorical structure as the axis of the virtual classroom, which focuses on the student and their levels of learning, for construction of the knowledge of a theoretical subject, making it visually attractive for the process of teaching-learning in B-Learning.

\section{PALABRAS CLAVE}

Entorno virtual temático, constructivismo, teoría del diseño, estructura metafórica.

\section{KEYWORDS}

Virtual thematic environment, Constructivism, Theory of design, Metaphoric structure. 


\section{INTRODUCCIÓN}

Para Sallán \& Bris (2004), la educación está en constante innovación y con bríos de alcanzar un verdadero sistema de calidad. Sin embargo, este concepto carece de un análisis objetivo, un continuo proceso de mejora y los correspondientes aportes económicos, culturales, tecnológicos y humanos de las Instituciones de Educación Superior en el Ecuador. Esto requiere del planteamiento de nuevas opciones basadas en la planificación y gestión educativa con proyección hacia la universalidad, el progreso y el bienestar social, permitiendo la inclusión de estrategias educativas que integren la tecnología en la formación de un ser integral, con aptitudes profesionales y un claro sentido crítico, reflexivo y de pertenencia (SEK, 2011). Este es el punto de equilibrio al cual debería propender el sistema educativo actual.

El planteamiento de esta propuesta radica en el establecimiento de nuevas formas de comunicación con un carácter lúdico e interactivo, en el que la construcción del conocimiento sea compartida y cuyos medios de comunicación, generen nuevas experiencias colaborativas, a través de recursos de lenguaje audiovisual y multimedia.

La implementación del entorno virtual temático, destinado a potenciar los procesos de enseñanza-aprendizaje, radica en las fases de operacionalización de aulas virtuales, que parten de la evaluación de necesidades formativas y conceptualización del curso, para luego proceder al diseño de actividades y recursos, ajustados a la metáfora gráfica, los mismos que son montados para su ejecución. La principal finalidad es obtener un espacio amigable para el grupo objetivo, mediante la constante actualización metodológica, didáctica y tecnológica, por lo que la estructura se basa en la Metodología PACIE (Presencia, Alcance, Comunicación, Interacción e E-learning), en sus bloques inicial, académico y de cierre, de manera que el estudiante, como protagonista del proceso, integre la realidad física con la virtual en la generación del nuevo conocimiento de Teoría del Diseño.

\section{CONTEXTUALIZACIÓN}

En base al diagnóstico realizado en la Escuela de Diseño Industrial de la Pontificia Universidad Católica del Ecuador-Ambato (PUCE Ambato) la versión de aula virtual en plataforma MOODLE para modalidad B-Learning, no resulta motivante para los estudiantes pese a los recursos que se utilizan; en vista de que la presentación es monótona y de uso obligatorio, por lo que no apoya al autoconocimiento en la búsqueda de soluciones creativas a un problema planteado.

Bajo este criterio, el aula virtual temática se fundamental en la búsqueda de un aprendizaje significativo basado en el descubrimiento, cuyo reto principal es el uso de un entorno diseñado con elementos iconográficos que motiven la conexión entre la idea (entorno de aula) y la realidad (lo que se espera). Este recurso se encuentra limitado actualmente a modalidad E-Learning, por lo que la información debe ser reinterpretada para su adaptación a B-Learning. 


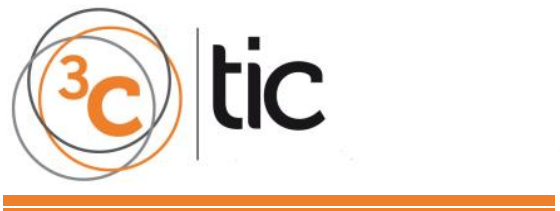

A este respecto, Bodero (2013), asegura que quienes usan de manera habitual estas herramientas, consideran que dicha estructura permite una comunicación óptima y mejora el uso de los recursos tecnológicos, por lo que el producto final, se enfoca en potencializar la enseñanza-aprendizaje de Teoría del Diseño dentro de la PUCE-Ambato.

\subsection{PRINCIPALES COMPONENTES}

De acuerdo a Sánchez, R. \& otros (2005), el aprendizaje constructivista es una de las principales teorías implementadas en los entornos de enseñanza-aprendizaje de modalidad B-Learning. Se trata de un modelo híbrido que integra estrategias didácticas de la modalidad presencial y de los modelos formativos de tecnologías web, con la única finalidad de generar un aprendizaje activo. La finalidad es alcanzar el objetivo pedagógico de construcción del conocimiento (aprender haciendo), combinando los hechos que el estudiante posee con nuevos conceptos que están a su disposición. Por esta razón es importante mencionar los aspectos aplicables a disciplinas como la Informática y el Diseño:

$\checkmark$ El conocimiento adquirido por los alumnos se debe a la interacción de estos dentro de un sistema colaborativo.

$\checkmark$ El aprendizaje colaborativo es la base para el aprendizaje, a través de la generación de ambientes de trabajo mixtos.

$\checkmark$ El trabajo se centra en problemas reales, cuyas soluciones no son dispuestas por el docente, sino que son enriquecidas por diferentes puntos de vista.

Por todo esto, es importante considerar que las nuevas metodologías de aprendizaje se dirijan hacia la calidad, basada en actividades reflexivas; $y$, cuyo sustento teórico se fundamente en la promoción del alumno hacia una estructura de conocimiento en la que incide su capacidad, motivación, contexto de enseñanza y su propia evaluación.

La siguiente figura describe los aspectos programáticos del proceso constructivista.

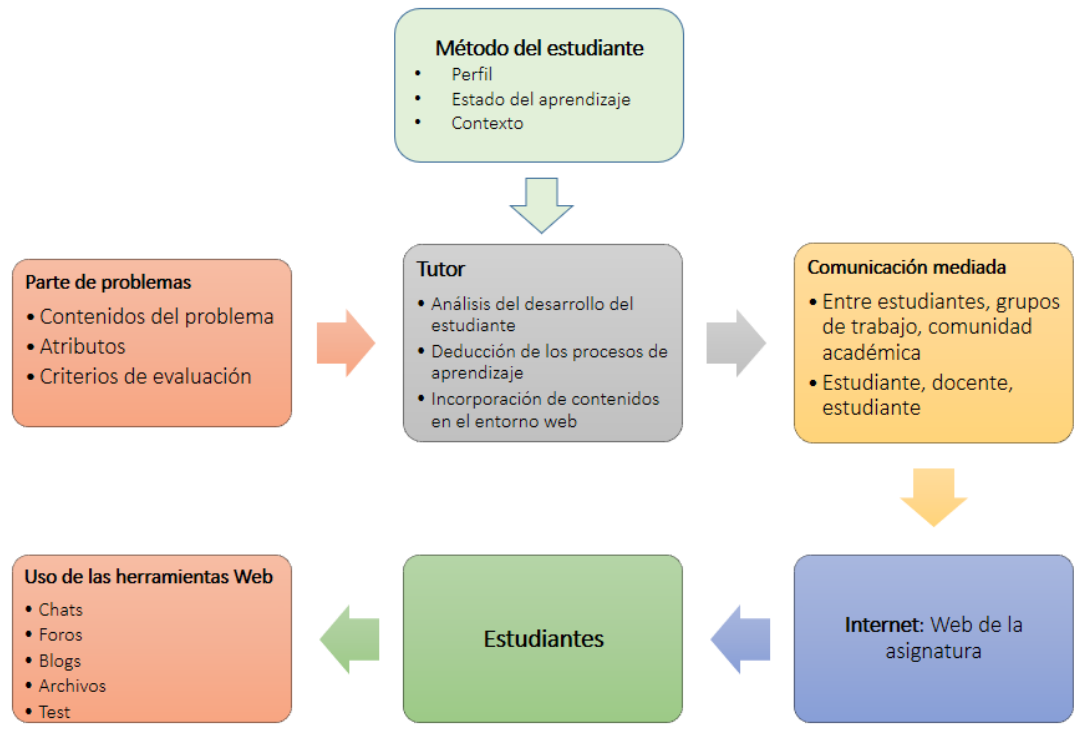

Figura 1. Estructura de aula virtual con aprendizaje constructivista. 


\subsection{EL METAAPRENDIZAJE Y LA METAEVALUACIÓN}

Según Chávez (2013), el metaaprendizaje hace referencia a la capacidad de evaluación del propio aprendizaje, con la finalidad de alcanzar eficiencia, y motivación para el cambio de conducta del ser humano, después del proceso cognitivo; la cual enfatiza los niveles de aprendizaje significativo y su grado de abstracción; así:

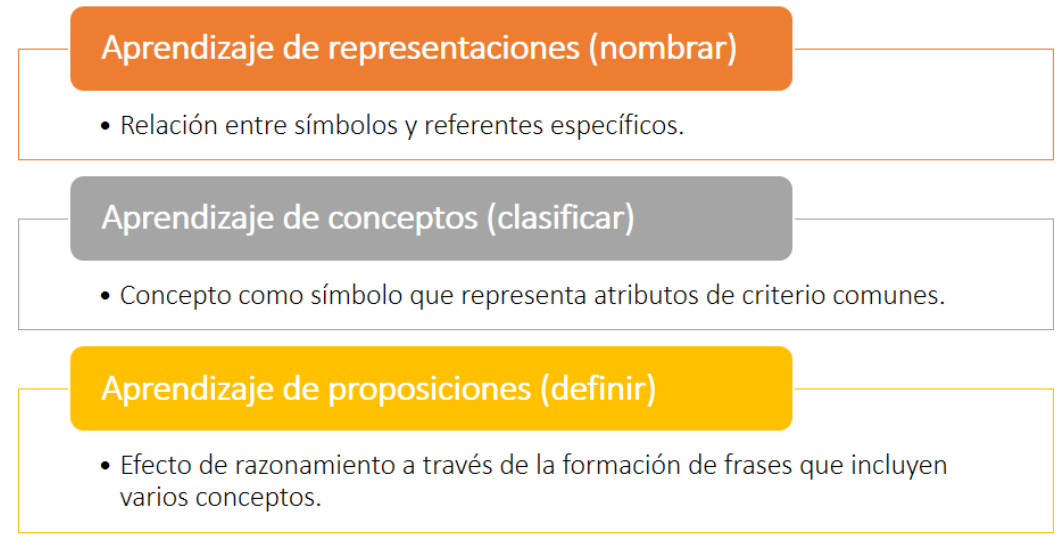

Figura 2. Niveles de aprendizaje según Ausbell (1995).

Bajo esta perspectiva, los diferentes niveles de aprendizaje significativo marcan un proceso para que el ser humano pase de la definición a la generación de nuevos conceptos mediante abstracciones continúas regidas por asimilación, inclusión o combinación.

Mateo (2003), establece a la metaevaluación como parte central del metaaprendizaje, rompiendo así con la complejidad del proceso evaluativo: tiempo y subjetividad. La finalidad es asegurar la calidad de los servicios evaluativos, con un proceso de autoevaluación que minimice la parcialidad, el error técnico y las dificultades administrativas. En respuesta a esta exigencia, el proceso de enseñanza-aprendizaje debe estar equilibrado entre actividades individuales y colectivas, con la finalidad de generar un proceso de reflexión, fundamentado en el análisis, la aplicación y la autovaloración. Para Delgado, M. \& Solano, A. (2013), las estrategias didácticas innovadoras deben tener una estructura presencial como grupos de discusión, recuperación de información, juego de roles y portafolios, combinadas con herramientas informáticas de foro, taller, wikis, entre otros, que son la base para la construcción del conocimiento.

\subsection{LA METÁFORA Y LA TEORÍA DEL DISEÑO}

De las conclusiones obtenidas por Bodero \& otros (2013), se define a la metáfora como una expresión con un significado diferente fuera del contexto habitual. Un aula virtual con estas características, es un espacio diseñado iconográficamente bajo una premisa, con el objetivo de que los participantes establezcan los nexos entre la idea y la realidad. 


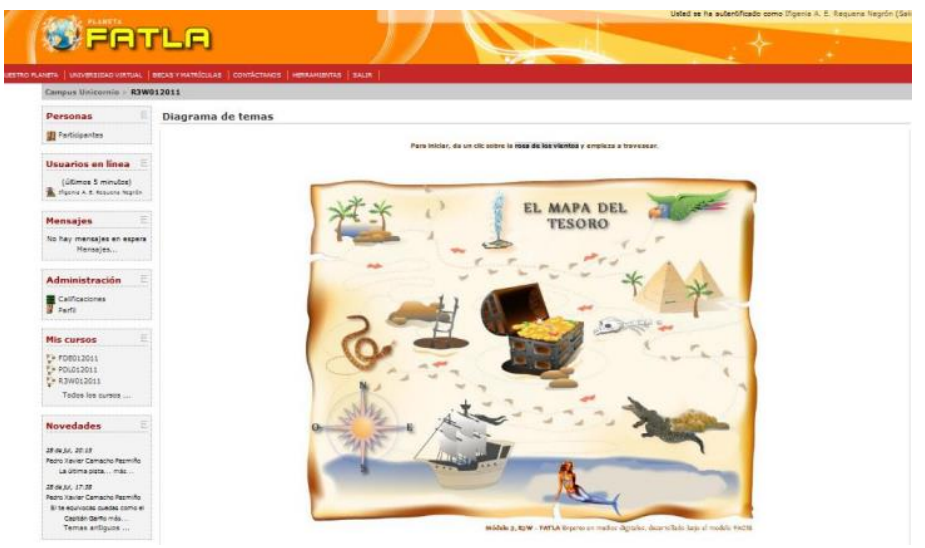

DOI: http://dx.doi.org/10.17993/3ctic.2017.58.27-41

Figura 3. Ejemplo de Aula Virtual Metafórica.

La finalidad de este tipo de aulas es que los participantes asuman el rol protagónico en función a una idea central, por lo que es importante incluir un lenguaje estructurado para el desarrollo de actividades. También es necesario establecer una relación entre el entorno de aprendizaje y su aplicación real, con un proceso de valoración periódica, desde los aspectos didácticos, la mediación educativa y los recursos tecnológico-culturales implementados. Las herramientas tecnológicas, deben propender a la interactividad sincrónica y/o asincrónica, para convertir al sistema de aprendizaje en atractivo y con profundidad de contenido, mediante:

$\checkmark$ Diseño de actividades que integren el uso de las herramientas web.

$\checkmark$ Preparación de recursos que integren las herramientas web y la correspondiente comprobación de funcionamiento dentro de la interfaz de ejecución del curso virtual.

$\checkmark \quad$ Integración de las herramientas en el desarrollo de los contenidos de la temática del aula virtual.

$\checkmark$ Valoración y monitoreo del uso de las herramientas web propuestas.

Hay que destacar que, dentro de la planificación de un curso virtual o semipresencial, resulta importante que las herramientas web utilizadas no se enfoquen en un sentido estético, sino que dinamicen el proceso de enseñanza-aprendizaje, por lo que cada una debe tener su uso específico, de acuerdo a la naturaleza de la asignatura. Por esta razón, teoría del diseño, como parte del área básica de formación de la Escuela de Diseño Industrial requiere de un planteamiento innovador que facilite el análisis histórico y metodológico, con una visión prospectiva y crítica en vista de que la actual estructura de MOODLE de la PUCE-Ambato es lineal y contiene los bloques de la siguiente figura. 


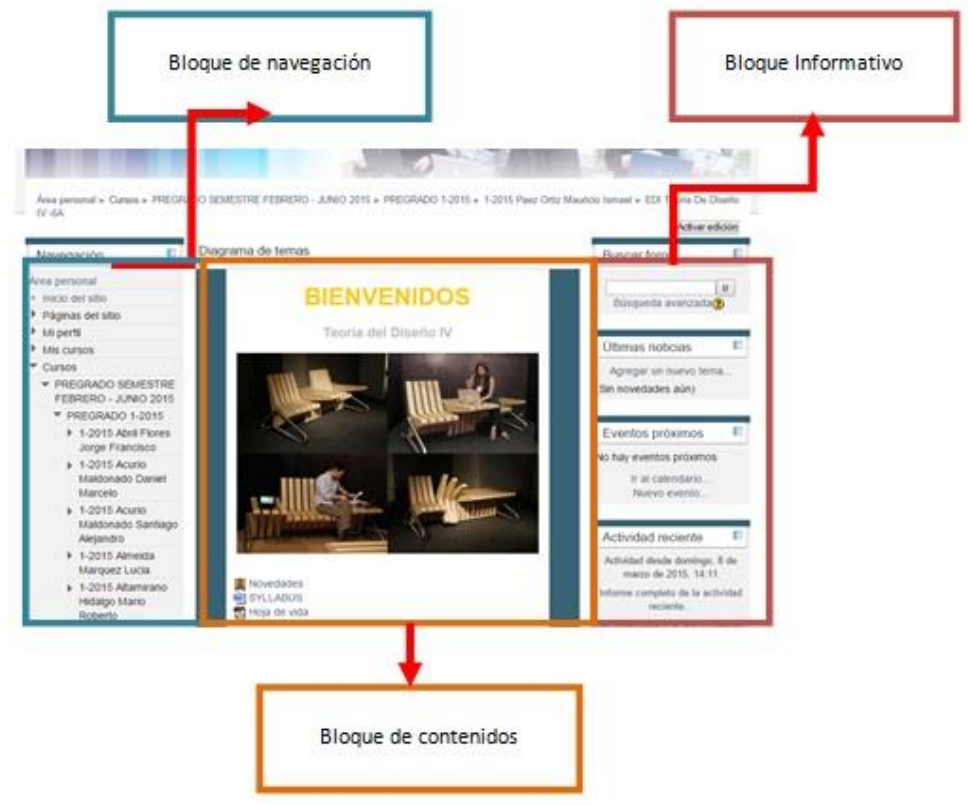

Figura 4. Estructura del aula virtual de la Asignatura de Teoría del Diseño IV.

Bajo este análisis, se plantea un aula virtual temática, con un ambiente de aprendizaje visual e interactivo, que influya en los aspectos didácticos, sociales y técnicos, a través del análisis de las necesidades particulares de aprendizaje de los participantes; y, el diseño de las secciones del aula virtual, guiadas por la metáfora gráfica, en función al siguiente proceso (Requena, I., 2015):

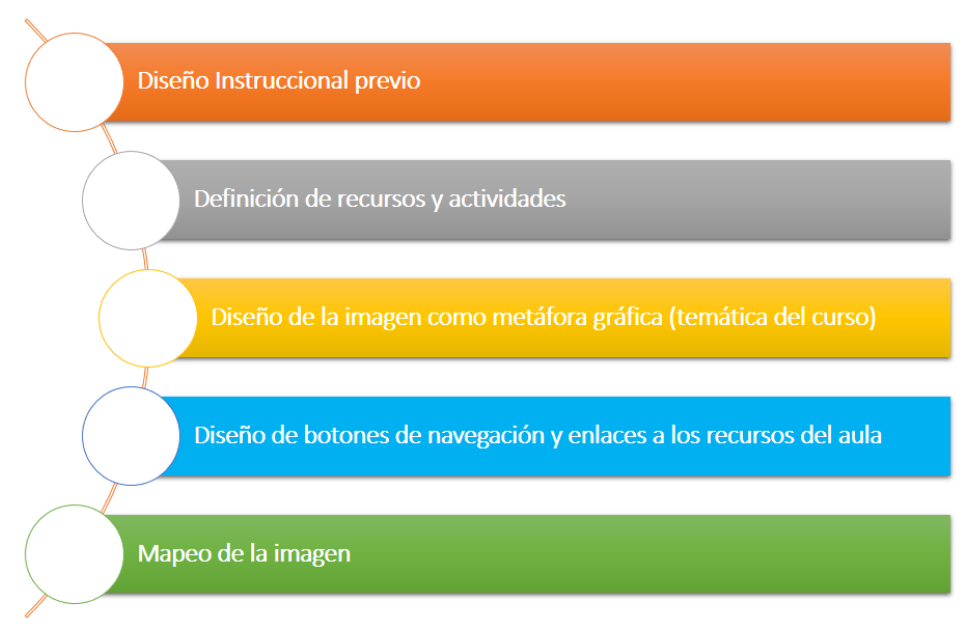

Figura 5. Proceso de construcción del aula temática.

En definitiva, la generación de un ambiente personalizado, basado en una planificación previa, contribuye para alcanzar los resultados de aprendizaje a través del uso de recursos tecnológicos, que más allá de la comunicación y la interacción, buscan motivar al estudiante hacia nuevos procesos de afianzamiento de sus conocimientos. 


\section{METODOLOGÍA}

La metodología central para este tipo de estructura se centró en la Operacionalización del Aula Virtual (Metodología y Fase operativa de un EVA, 2013), la cual se selecciona en función al proceso de implementación de un aula virtual temática, ajustada a un modelo constructivista de enseñanza-aprendizaje.

\subsection{DIAGNÓSTICO}

El enfoque del diagnóstico de necesidades formativas es de tipo cualitativo, para que se evalúen los datos correspondientes al uso de entornos virtuales, sus recursos y actividades. También la incidencia en el proceso de enseñanza-aprendizaje (constructivismo), tipo de metáfora gráfica y nivel de la asignatura de aplicación, mediante encuestas aplicadas al grupo objetivo conformado por 65 estudiantes de las asignaturas de Teoría del Diseño; y, 20 docentes de la Escuela de Diseño Industrial. Estos resultados son empleados para la conceptualización y desarrollo del curso.

En el caso de los estudiantes, se toma como referencia los siguientes datos obtenidos:

$\checkmark$ Resulta importante manejar una planificación de la clase, aplicando una estructura secuencial de las actividades a través de los recursos del entorno virtual.

$\checkmark$ Para el planteamiento de un aula virtual temática, es importante conocer los elementos más utilizados por los estudiantes de acuerdo a la planificación de clases, enfatizando en la exposición de la información y el uso de chats y foros.

$\checkmark$ La experimentación es un factor clave, a través de la implementación innovadora de recursos virtuales.

La temática seleccionada es "Visitando museos", mediante la cual el participante recorre un espacio como parte de su proceso de enseñanza-aprendizaje.

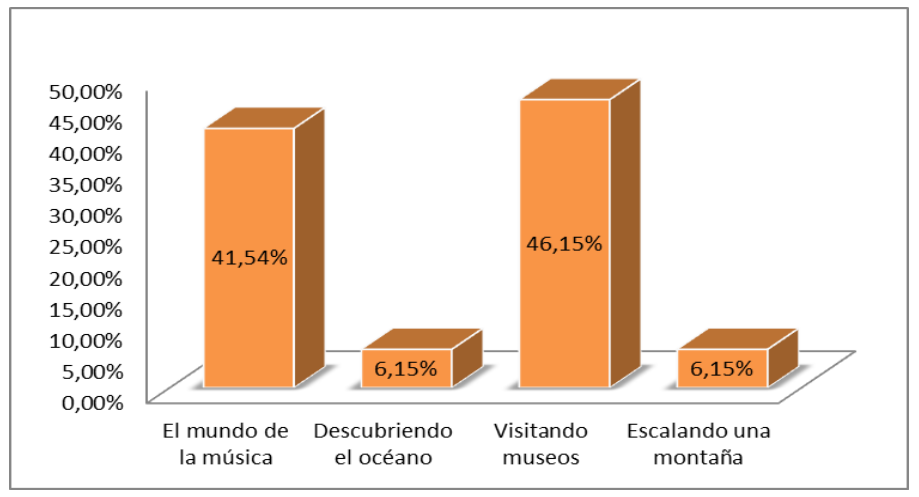

Gráfico 1. Definición de la temática.

Fuente: Elaboración propia.

En el caso de los docentes, los resultados hacen referencia a lo siguiente:

La distribución de la información se convierte en el aspecto fundamental; sin embargo, actividades como la experimentación, evaluación y enlaces externos, deben ser equitativas. 
$\checkmark$ El aula virtual debe fundamentarse en el aprendizaje por descubrimiento, considerando el rol protagónico del estudiante, mediante la síntesis conceptual a través de imágenes con una identidad gráfica homogénea.

$\checkmark$ La prueba piloto debe realizarse con la asignatura de Teoría del Diseño I, debido a su carga horaria inferior, de manera que sea más práctico su planteamiento virtualtemático.

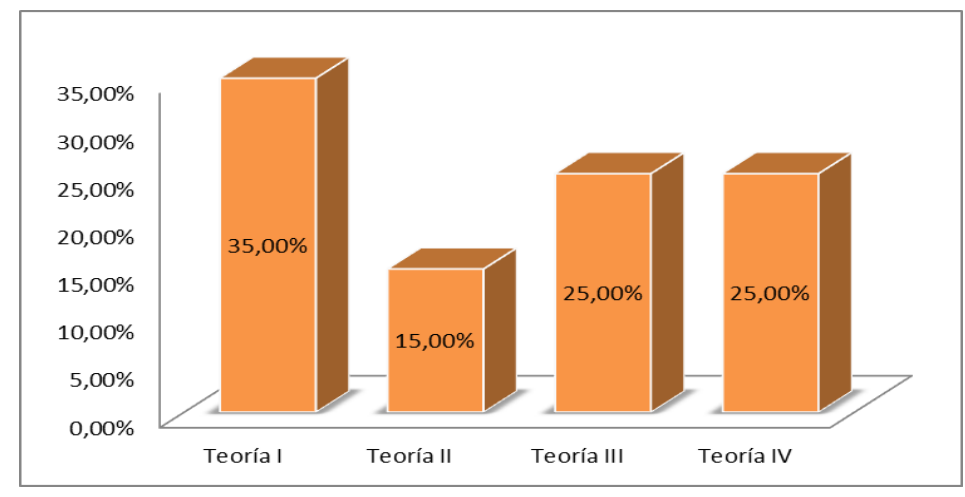

Gráfico 2. Asignatura de aplicación. Fuente: Elaboración propia.

\subsection{ANÁLISIS}

Como resultado del diagnóstico se obtienen los requerimientos que rigen la propuesta:

$\checkmark$ El aula virtual se plantea con una estructura motivadora hacia la interacción del grupo de participantes, de manera que el entorno de aprendizaje sea útil en la generación del nuevo conocimiento.

$\checkmark$ La integración de actividades se basa en la innovación, considerando un proceso de aprendizaje autoevaluado, para lo cual es importante el uso de recursos multimediales, enfocados al intercambio de información, con la finalidad de una evaluación integral centrada en el aprendizaje por descubrimiento.

$\checkmark$ Debido al interés de estudiantes y docentes con respecto a la experimentación con el aula virtual, se selecciona a Teoría del Diseño I para la prueba piloto, enfatizando en la experiencia docente, ya que, por la complejidad de los contenidos, es recomendable empezar por la del nivel inferior, cuya carga horaria es de 2 horas semanales; de manera que una vez evaluado su funcionamiento, la aplicación se podrá extender hacia asignaturas de mayor complejidad.

$\checkmark$ La necesidad formativa en este tipo de aulas, la conforma la síntesis conceptual a través de imágenes, por lo que el diagnóstico arrojó como resultado, la aplicación temática "Visitando museos", con una identidad gráfica homogénea desde lo visual hasta lo didáctico, mediante el uso de recursos y actividades físicas y multimediales. 


\subsection{MÉTODO APLICADO}

DOI: http://dx.doi.org/10.17993/3ctic.2017.58.27-41

El producto final es un aula virtual temática, cuyo planteamiento parte de una Metodología de Operacionalización para el Diseño y Desarrollo de un proceso formativo bajo Entornos Virtuales, para lo cual se aplica una metáfora que facilita la selección de los elementos iconográficos para la secuencia de actividades entre los bloques de desarrollo de la cátedra de Teoría del Diseño I de la Escuela de Diseño Industrial de la PUCE-Ambato.
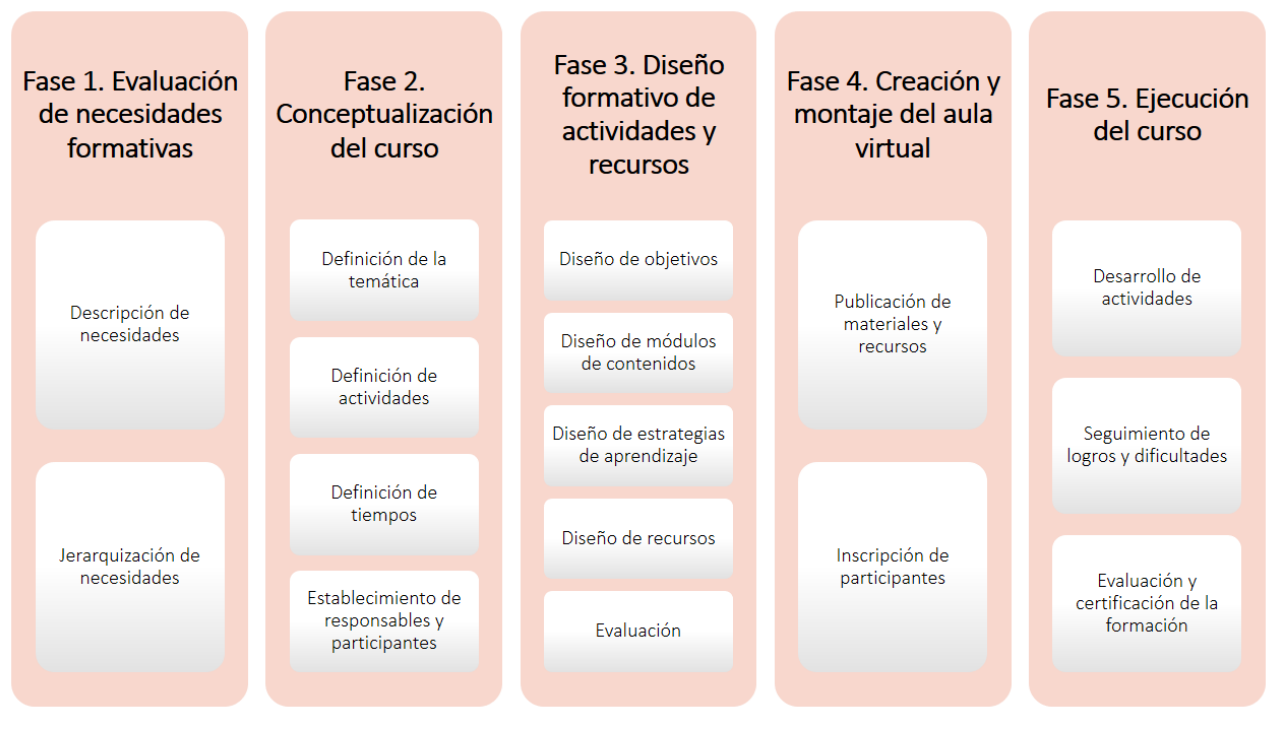

Figura 6. Metodología y fases operativas de un EVA.

\section{RESULTADOS}

Los contenidos del aula virtual basada en la metáfora gráfica denominada "Museo del Descubrimiento" están estructurados en tres parciales, de acuerdo a la planificación de la Escuela de Diseño Industrial. Los bloques de contenidos se ajustan a la Metodología PACIE y están organizados en función a la metáfora gráfica, la cual emplea estrategias constructivistas.

A continuación, se describe cada bloque del aula virtual.

\section{Estructura del Bloque Inicial}

\begin{tabular}{|c|c|c|}
\hline Unidad 1. Introducción & Estrategia didáctica & Recurso tecnológico \\
\hline $\begin{array}{l}\text { Bienvenida } \\
\text { Agenda } \\
\text { Diagnóstico } \\
\text { Ayuda }\end{array}$ & $\begin{array}{l}\text { Exposición didáctica } \\
\text { Publicación } \\
\text { Preguntas al grupo } \\
\text { Interacción }\end{array}$ & $\begin{array}{l}\text { VOKI } \\
\text { JOOMAG } \\
\text { EDILIM }\end{array}$ \\
\hline
\end{tabular}

Fuente: elaboración propia. 


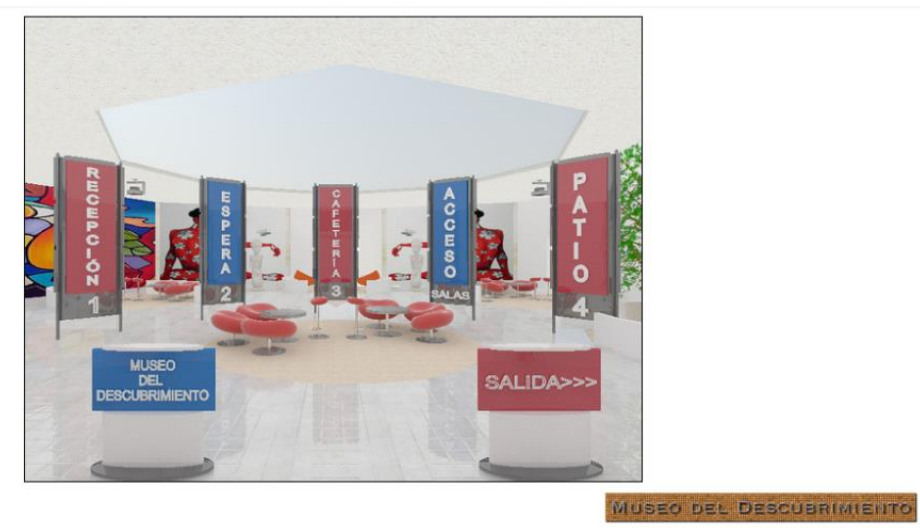

Figura 7. Bloque principal.

\section{Estructura del Bloque Académico I}

\begin{tabular}{|c|c|c|c|}
\hline $\begin{array}{l}\text { Unidad } \\
\text { Antiguo }\end{array}$ & 2. Arte & Estrategia didáctica & Recurso tecnológico \\
\hline $\begin{array}{l}\text { Egipto } \\
\text { Grecia } \\
\text { Roma }\end{array}$ & & $\begin{array}{l}\text { Exposición didáctica } \\
\text { Subgrupos de discusión } \\
\text { Recuperación de la información } \\
\text { Contrato de aprendizaje } \\
\text { Valoración de necesidades } \\
\text { Trabajos de investigación con } \\
\text { retroalimentación }\end{array}$ & $\begin{array}{l}\text { YOUTUBE } \\
\text { ISSUU } \\
\text { SLIDESHARE } \\
\text { FACEBOOK } \\
\text { Articulate Engage } \\
\text { Hotpotatoes }\end{array}$ \\
\hline
\end{tabular}

Fuente: elaboración propia.

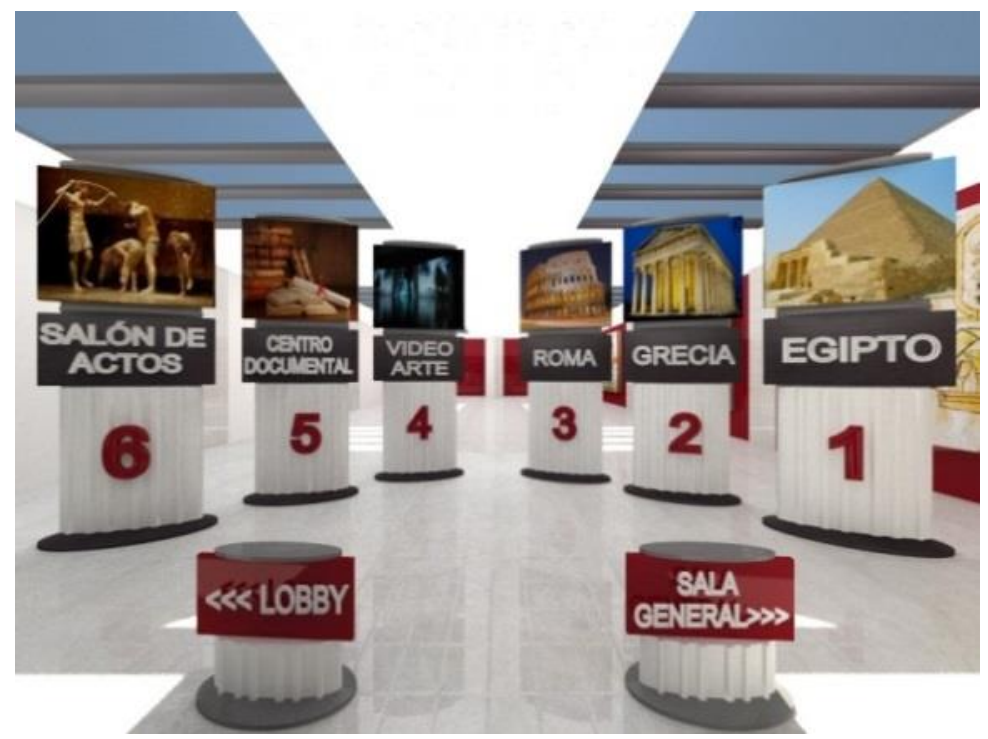

Figura 8. Sala de Exposición I-Unidad II. 


\section{Estructura del Bloque Académico II}

\begin{tabular}{|c|c|c|}
\hline Unidad 3. Arte Moderno & Estrategia didáctica & Recurso tecnológico \\
\hline $\begin{array}{l}\text { Gótico } \\
\text { Barroco } \\
\text { Rococó }\end{array}$ & $\begin{array}{l}\text { Exposiciones didácticas y } \\
\text { digitales } \\
\text { Trabajos de investigación con } \\
\text { retroalimentación } \\
\text { Juegos de rol } \\
\text { Valoración de necesidades } \\
\text { Trabajo por proyectos }\end{array}$ & $\begin{array}{l}\text { SCRIBD } \\
\text { Google docs } \\
\text { PREZI } \\
\text { YOUTUBE } \\
\text { Enlaces externos } \\
\text { Test en línea }\end{array}$ \\
\hline
\end{tabular}

Fuente: elaboración propia.

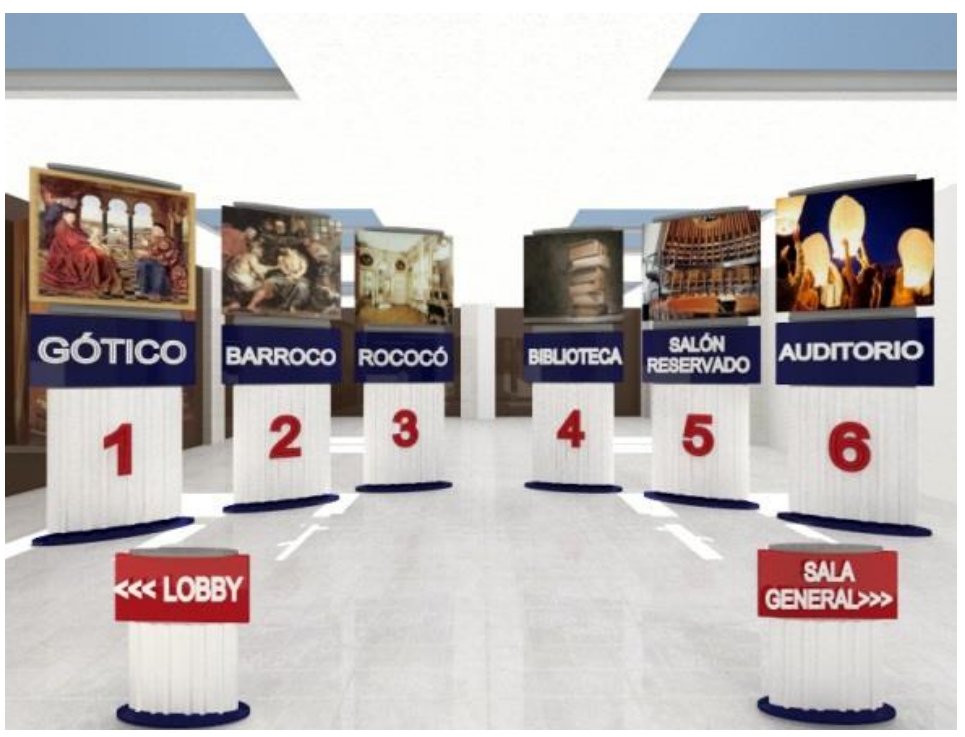

Figura 9. Sala de Exposición II -Unidad III.

\section{Estructura del Bloque Académico III.}

\begin{tabular}{|c|c|c|}
\hline Unidad 4. La Industria & Estrategia didáctica & Recurso tecnológico \\
\hline $\begin{array}{l}\text { La Revolución Industrial } \\
\text { La Escuela de La Bauhaus }\end{array}$ & $\begin{array}{l}\text { Exposiciones didácticas y } \\
\text { digitales } \\
\text { Trabajo en equipo } \\
\text { Contrato de aprendizaje } \\
\text { Trabajos de investigación } \\
\text { con retroalimentación }\end{array}$ & $\begin{array}{l}\text { SCRIBD } \\
\text { Lucidchart } \\
\text { Articulate engage } \\
\text { Youtube } \\
\text { Rubistar } \\
\text { Comunidad de aprendizaje de } \\
\text { google }\end{array}$ \\
\hline
\end{tabular}

Fuente: elaboración propia. 


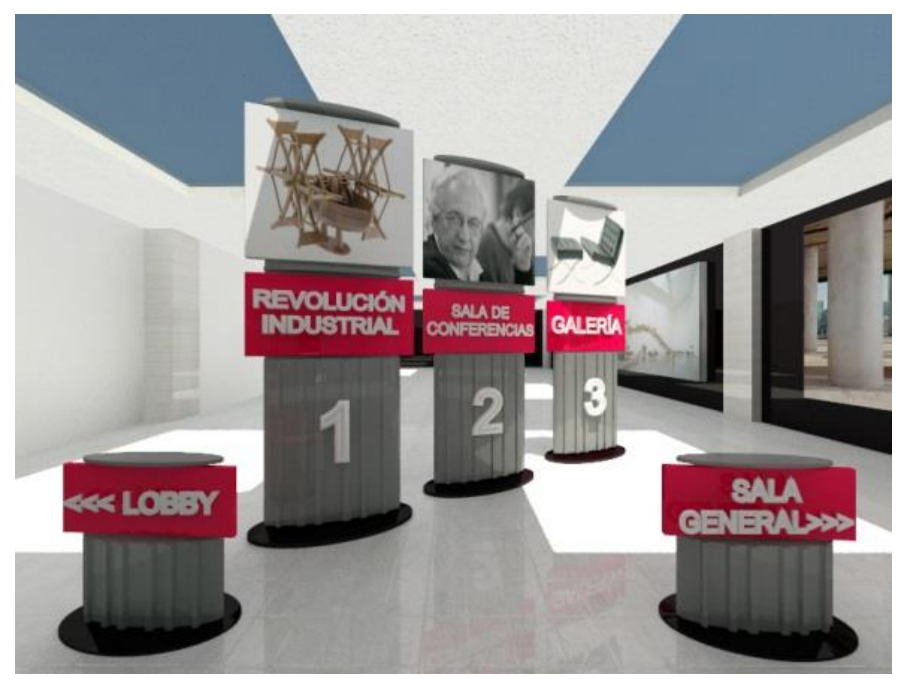

Figura 10. Sala de Exposición Central - Unidad IV.

\section{Estructura del Bloque de Cierre.}

\begin{tabular}{|l|l|l|}
\hline Unidad 5. Conclusiones & Estrategia didáctica & Recurso tecnológico \\
\hline Exposiciones finales & Exposiciones & Blog \\
Sugerencias & Portafolio & Foro \\
Publicación de notas & Valoración de necesidades & Encuesta de google \\
Evaluación & Tablón de anuncios. & drive \\
\hline
\end{tabular}

Fuente: Elaboración propia.

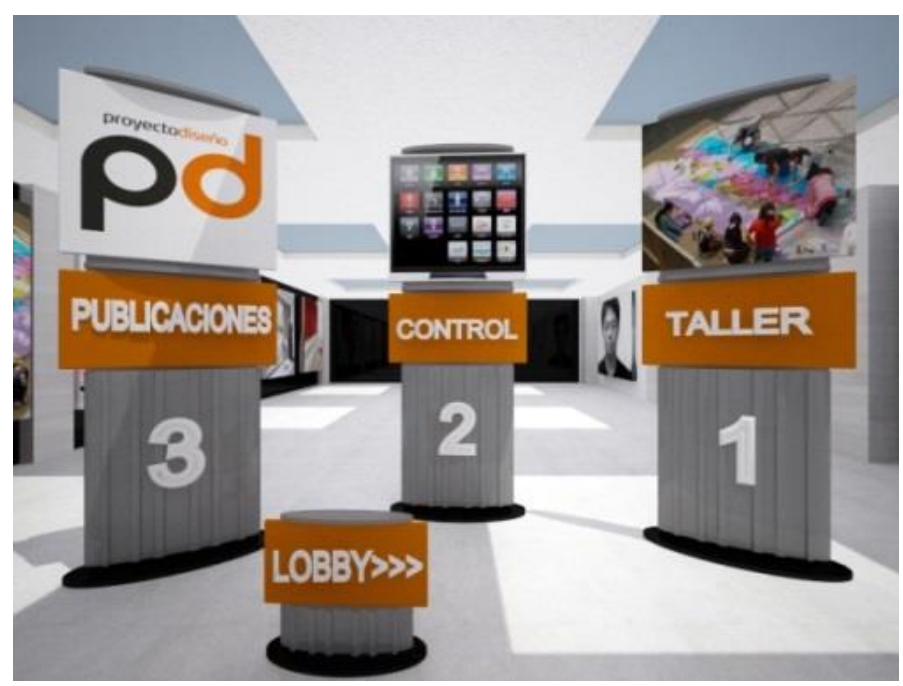

Figura 11. Sala Temporal - Unidad V.

El número de horas se ha distribuido de manera equitativa entre los 3 parciales, alcanzando un total de 36 horas semestrales de acuerdo a la planificación. Los recursos empleados, basados en los estilos de aprendizaje, buscan la interacción de los participantes, con base en la secuencia gráfica y la inclusión de recursos tanto internos como externos. 


\section{CONCLUSIONES}

DOI: http://dx.doi.org/10.17993/3ctic.2017.58.27-41

De acuerdo a la valoración de funcionamiento del aula virtual temática, se concluye que:

$\checkmark$ El desarrollo de un aula virtual temática involucra un alto nivel de exigencia del docente, en lo académico, tecnológico y didáctico, ya que esta estructura parte del diagnóstico de necesidades del usuario y del entorno de aprendizaje, para la generación de recursos innovadores como presentaciones audiovisuales publicadas en revistas o videos; $y$, actividades colaborativas, con archivos almacenados en la nube. Están encaminados a la comunicación e interacción significativa y colaborativa (metaaprendizaje); y, cuya evaluación guíe al participante a la transformación de la acción formativa en un proceso estimulante.

$\checkmark \quad$ La clave para el diseño de este tipo de aulas lo constituye la metáfora gráfica como concepto para el desarrollo de clases, ya que esto implica el análisis de las imágenes para la visualización del aula; y, la relación entre las secciones de la planificación, que volverán al recorrido virtual, fácil e intuitivo. Sin embargo, la adaptación de este sistema mixto, involucra una mayor asesoría por parte del tutor, como guía del aprendizaje.

$\checkmark$ La identidad gráfica conceptual del aula es el "Museo del Descubrimiento", la cual está estandarizada en las diferentes salas, mediante la edición de códigos HTML para el mapeo de imágenes, empleando un lenguaje unificado, enfocado en los estilos de aprendizaje de los estudiantes. Los recursos generados de manera autónoma deben seguir la línea de la metáfora gráfica, considerando su inclusión en el aula virtual, mediante el bloque sidebar que facilita ocultar completamente los recursos y actividades.

$\checkmark$ La aplicación de cuestionarios para el diagnóstico de necesidades, dan como resultado las pautas para el diseño del aula virtual. Sin embargo, se debe mencionar que la aplicación de una temática, en este tipo de entorno de aprendizaje, no garantiza por sí sola, la obtención de resultados positivos del estudiante, pues es la planificación previa, la que guiará los procesos y el alcance de metas del estudiante, el docente, la unidad académica y por ende la institución. 


\section{REFERENCIAS BIBLIOGRÁFICAS}

Ausubel, D., Novak, J. y Hanesian, H. (1995): Psicología educativa. Un enfoque cognoscitivo. México. Trillas.

Bodero, E., Castillo J., Marconi, G., \& otros (2013). Estrategias Pedagógicas en Aulas Virtuales.

Chávez, J. (2013). Metaaprendizaje:¿Cómo Aprendemos? ¿Por Qué no Aprendemos?.

Sallán, J. G., \& Bris, M. M. (2004). Las instituciones educativas en la encrucijada de los nuevos tiempos: retos, necesidades, principios y actuaciones. Tendencias pedagógicas, (9), 21-44.

Delgado Fernández, M., \& Solano González, A. (2013). Estrategias didácticas creativas en entornos virtuales para el aprendizaje. INIE.

Mateo, I. D. (2003). Metaevaluación:¿ Por qué y para qué?. Revista cubana de educación superior, 23(3), 43-58.

Medina, P. (2013). Compilado sobre Metodología y Fase Operativa de un EVA. Cómo montar un aula virtual.

Requena Negrón, I. (2015). Enfoques Metafóricos e Iconográficos: Aplicación en la personalización de espacios virtuales de aprendizaje. Revista digital La Pasión del Saber (7ma edición). Universidad José Antonio Paez ISSN 2244 - 7857

Sánchez-Cortés, R. S., Manso, A. G., Allende, J. S., Díaz, P. M., \& Peinado, A. R. (2005). BLearning y Teoría del Aprendizaje Constructivista en las Disciplinas Informáticas: Un esquema de ejemplo a aplicar. Recent Research Developments in Learning Technologies, $1-6$.

Syllabus de Teoría del Diseño. (2015). Carrera de Diseño Industrial, Pontificia Universidad Católica del Ecuador Sede Ambato.

Universidad Internacional SEK. (2011). Modelo Educativo basado en competencias de formación integral. Introducción, 4-8. Ecuador. 